\title{
Conceptual Framework Of Double System Education (PSG) Evaluation Using Cipp Model
}

\author{
Rahmania Sri Untari \\ Doctoral Student of Vocational Education Program, \\ Post Graduate, State University of Malang \\ Jl. Semarang Indonesia $5 \mathrm{M}$ alang, Indonesia \\ rahmania.sriuntari@umsida.ac.id
}

\begin{abstract}
Dual System Education is an education system in Vocational High School which is adopted from Germany. This Education System integrates learning activities in schools and PSG activities in the Business and Industrial World (DUDI). The evaluation used is the CIPP model (Context, Input, Process, Product) de veloped by Stufflebeam. This conceptual framework is used to define the dimension stage and identify elements of context, input, process and product in the implementation of Dual System Education. In the context evaluation of the evaluation objectives are: (a) the purpose of PSG in schools; (B) planning of PSG implementation; And (c) PSG needs and opportunities. In the evaluation of inputs of the evaluation objectives are: (a) PSG implementation strategy, including: (1) procedures (PS G materials, implementation time, methods and implementation patterns); (2) cooperation with DU/DI (mentoring role, cooperation script, lobby). In the evaluation (process) the process of evaluation objectives are: (a) the implementation of PSG ie time, student activity journal, implementation of guidance; (B) PSG constraints. In the evaluation (product) product evaluation target of the students, which see the ability or competence of students in accordance with the goals proclaimed by the Ministry of Education and Culture.
\end{abstract}

Keywords-Evaluation, Dual System Education, CIPP Model

\section{INTRODUCTION}

The government has put better focus on the education system. Various efforts are made to meet the quality of graduates who are ready to enter the job market. One of the strategies is implementing link and match policy that applies to all types and levels of education in Indonesia through the Ministry of Education and Culture. The implementation of the Vocational School Curriculu m began in the academic year 1994/1995 which adopted Dual System as the main scheme. This system itself was adopted from Germany and it was potentially implemented in schools and industries or companies from level one to level three. Like the study, the approach of The Dual System Education (PSG) was inseparable with the link and match policy that became the main scheme of vocational school curriculum implementation [1].
The Implementation of education with a dual system in Indonesia is expected to create reliable workers in their fields. This issue is brought up since in Germany, the certificate of competence that is is sued by the internship companies is widely recognized in the job market. This certificate would benefit the graduates since it would be easier for them to find suitable jobs that match with their fields. Meanwhile for the companies, this practice could plummet the recruitment cost.

As a sub system of national education that is responsible for providing competent middle class workers, Vocational Schools (SMK) are forced to prepare graduates whose skills are needed by the job market. The Industrial Internship (PRAKERIN) is a part of Dual System (PSG) which serves as an innovation in Vocational Schools program where students do an internship in companies and industries and it is seen as an integral part of training and learning process in the Vocational Schools (SMK).

In Indonesia, the training participants from Vocational Schools undergo months of Industrial Internship during their 3 years study. PSG through Industrial Internship is a substantial step to make the vocational education and training system become more relevant to the job market in order to create skillful graduates.

The gaps and uncertain quality of graduates from some educational institutions as expected by the business / industrial world (DU / DI) becomes an issue of the absence of interrelationship between education and DU / DI. The incompatible skills possessed by graduates with the type of skills required to handle particular work or positions is the concrete evidence of the problem [2].

Reckoning the importance of PSG for SMK students and the reality on the field, raises a question "Is the dual system truly able to fulfill Vocational School's expectations and goals to prepare human resources?". Answering this question requires an evaluation of its implementation. There aren't many schools, or even just a few that have evaluated the implementation of PSG.

Evaluation is a systematic fact gathering of the learning process to determine whether changes occur to learners and how 
far does it affect the lives of learners. Evaluation is a study that has been established and implemented in order to help researchers to assess the value and benefits of an object. This model also visualizes the conceptual representation of activity about the relationship between the various elements involved in the activity. Using this model, assessments can be done fully and significantly. The researcher chose Stufflebeam CIPP evaluation model because of its effectiveness to get formative summative results and to find decisions as well as problemsolving the issue. In this paper, the author tries to define the dimension stage and identify elements of context, input, process and product in the implementation of Dual System Education. This study aims to define the dimensional stage and identify elements of context, input, process, and product in the implementation of Dual System Education (PSG).

\section{LITERATURE REVIEW}

\section{A. Dual System Education (PSG)}

Dual System Education (PSG) is an education system with activities included in it. Therefore, students would have learning and working experience at the same time. And it is aligned with the development of human civilization that causes an advanced working-learning culture which fits with the development of science and technology. A dual system is also a form of professional skills education which integrate systematically and synchronously education programs in school and skill acquisition program that are obtained through direct working experience in the working world, and it is directed to achieve a level of professional expertise.

Multiple System Education (PSG) is viewed as a system. If all components involved are aware of their functions to maximize the function system, it will create a permanent form of cooperation between DU / DI and schools with mutual beneficial. Through such cooperation, optimum output and outcome can be achieved by creating skilled human resources whose skills are needed by the society and the job market [1].

\section{B. Program Evaluation}

Amri, (2013: 217) explains that evaluation can also be interpreted as a process of planning, obtaining, and providing information that is essential to make alternative decisions [3]. Evaluation can be used to check the success rate of programs related to the program environment and judgment, whether activities are forwarded, postponed, upgraded, institutionalized, accepted, or rejected. Decisions are taken as performance indicators at each stage of evaluation in three categories: low, moderate, and high.
Evaluation is a process of providing information that can be taken into consideration to determine the price and value (worth and merit) of the objectives, design, implementation and impact in order to make decisions easier, accountability and improve understanding of phenomena. According to the formula, the core of evaluation is the provision of information that can be used as consideration in making decisions [4].

Programs are actions or activities designed to implement policies in unlimited time. Certain policies are general and programs are made to realize the policies [5]. Program evaluation is a series of activities conducted deliberately to see the success rate of the program. There is some understanding of the program itself. So it can be concluded that evaluation is a process to collect information related to a predetermined program and the information will be used by the users related to the continuity of the next program.

\section{Evaluation Context Input Process Product (CIPP)}

The evaluation model used in this conceptual framework is the evaluation of the Context Input Process Product (CIPP). The CIPP evaluation model was developed by Daniel Stufflebeam in 1966. Stufflebeam defines evaluation as a process of delineating, obtaining and providing useful information for decision making. By looking at the explanation, then the evaluation step is to analyze the program based on some components. According to Stufflebeam, Context Evaluation is used to answer things needed. This evaluation identifies and assesses the needs of which the program is based. In the context evaluation aims to make decisions in planning.

Input Evaluation is designed to answer things to do . This evaluation identifies and the problems, assets, and opportunities to help decision-makers define goals, priorities, and helps broader groups of users to assess the objectives, priorities, and benefits of the program, assess alternative approaches, action plans, staff plans, And budgets for feasibility and potential cost effectiveness to meet needs. Evaluation process attempts to find answers whether the program is being implemented. This evaluation tries to access the implementation of the plan to help the staff carry out the activities and then help the wider user group to assess the program and interpret the benefits. Product evaluation is directed to find answers whether the program is successful or not. This evaluation tries to identify and access both planned and unplanned outcomes and benefits, whether short or long term.

The designs of CIPP model evaluation can be illustrated in Fig. 1 and Fig. 2 below: 


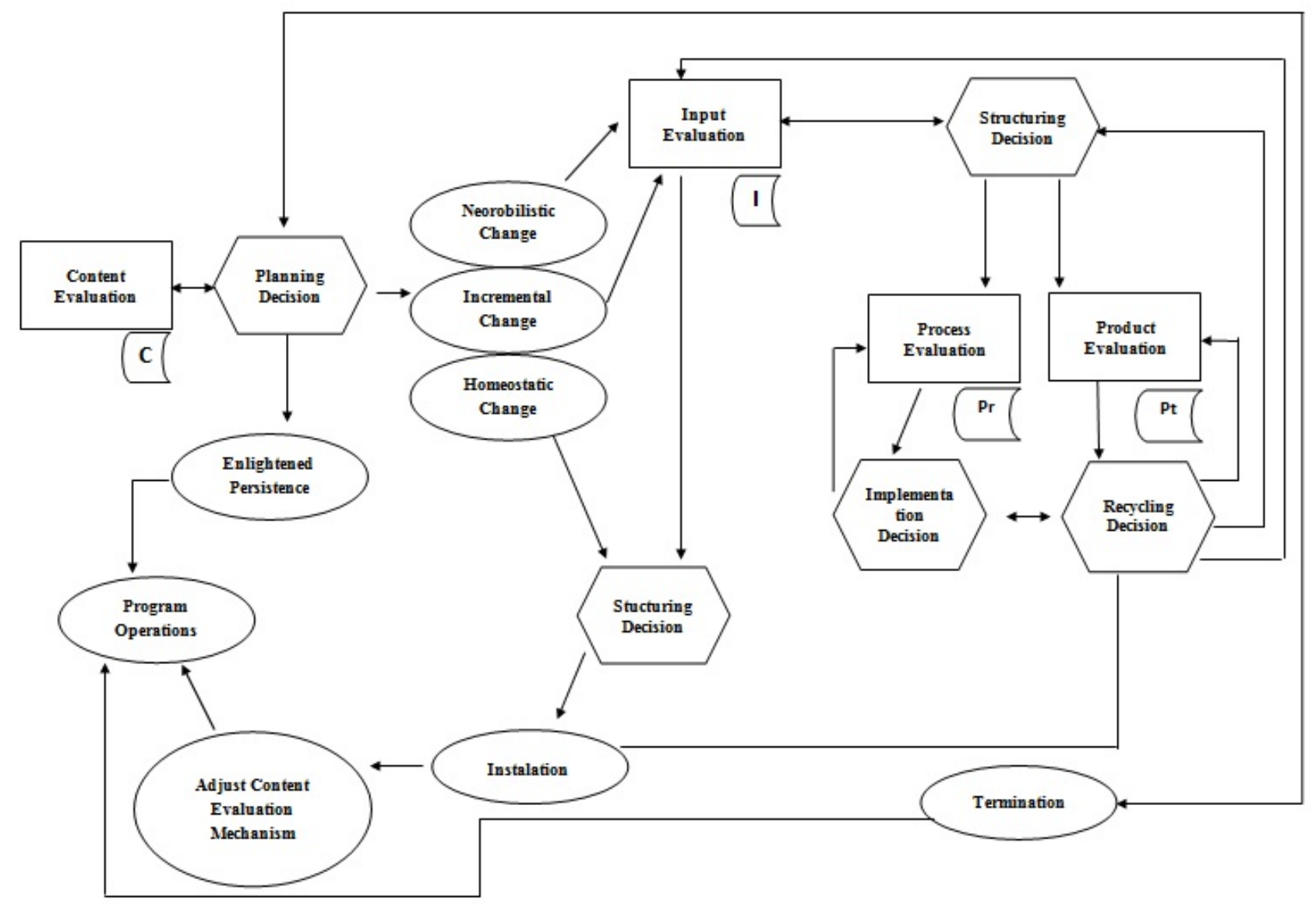

Fig. 1. CIPP Evaluation Design [6]

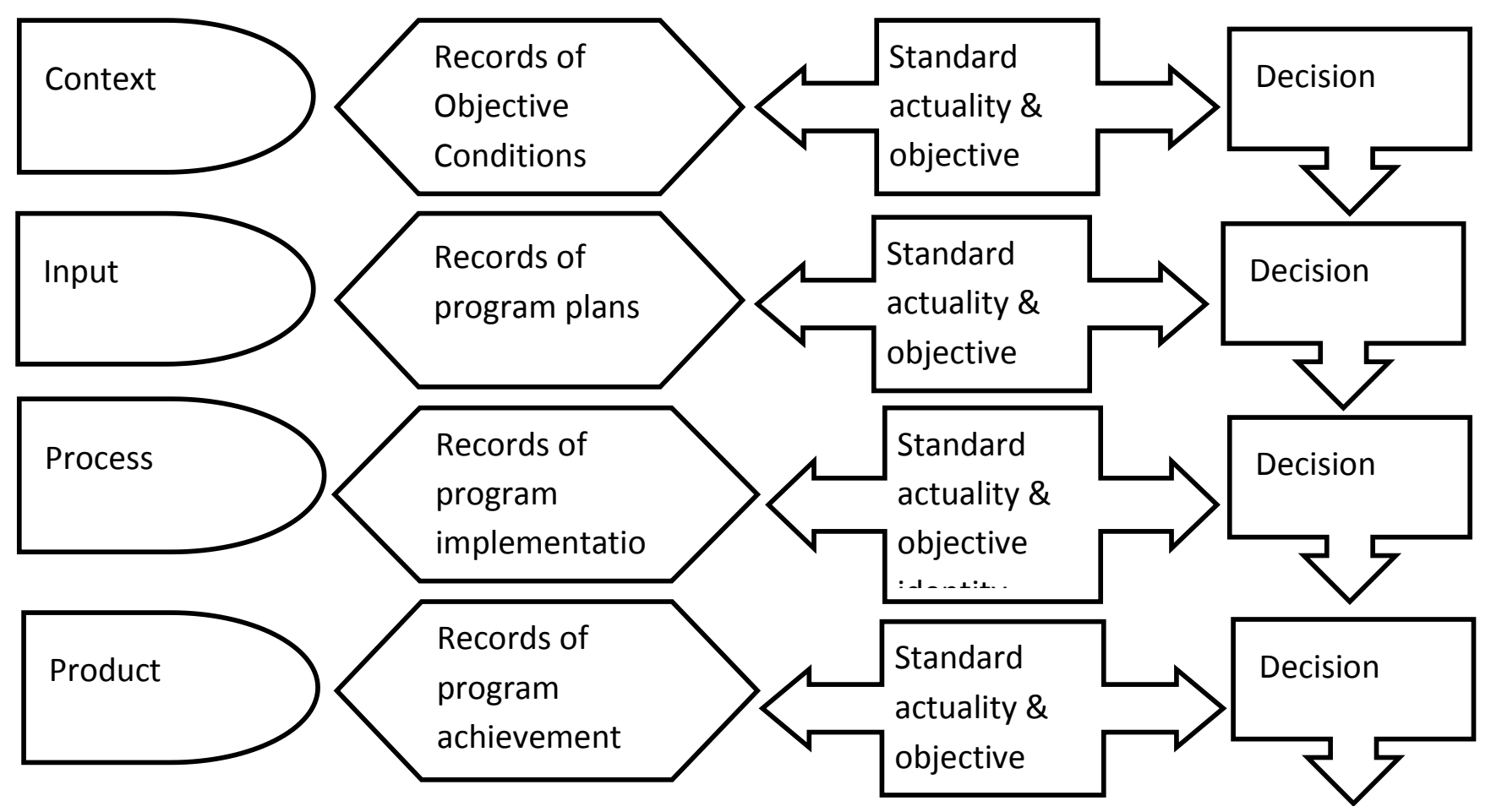

Chart 2. Research Design [7] 
The charts above have described how the evaluation process in the conceptual framework is done. Here are the evaluation goals at each stage:

$$
\begin{aligned}
& \text { C } P \text { Context Evaluation } \\
& \text { The objectives of the context evaluation are: } \\
& \text { 1. The purpose of PSG in school } \\
& \text { 2. PSG Implementation Plan } \\
& \text { 3. PSG Needs and Opportunities }
\end{aligned}
$$

I $=$ Input Evaluation

The objectives of the input evaluation are:

1. PSG Implementation Strategy, including:

Procedures (PSG material, execution time, methods and implementation patterns)

Cooperation with DU / DI (mentoring role, cooperation script, lobbying)

$\operatorname{Pr}=$ Process Evaluation

The evaluation process will be seen in the components:

1. Implementation of PSG

Time

Student activity journal

Implementation of guidance

2. PSG constraints

Pt = Product Evaluation

The objective of product evaluation is to look at students' skills or competence based on goals planned by Ministry of Education and Culture.

\section{DISCUSSION}

\section{A. Context}

In this section the writer will talk about the purpose of PSG, planning, needs and opportunities. Setting objectives for a program is very important, because it is the basis for a process. If the goal is clear, the process will run effectively and efficiently to achieve it. The formulation of objectives will also make it easier to achieve.

One of the goals of PSG is to produce graduates who have the knowledge, skills and work ethics in accordance with the demands of employ ment. The education process is inevitably tied to the work world. PSG activities that are implemented in the world of work are expected to minimize the gap between students' skills and the work world, even if it can be eliminated, so students are ready to enter the workforce after graduating.
From the students' point of view, it is said that learning outcomes will be more meaningful because after completing High School they will have professional skills. It seems like there is a guarantee that students really get the field experience for $100 \%$ as what the school expected. Experience at schools needs to be adjusted to make it relevant to the activities of the company.

What needs to be considered is continuous improvement in the program. This change requires special studies, experts, even the formation of special committees since the implementation process requires more mature planning. However, when it comes to preparation since students enter SMK, it is necessary to introduce PSG programs deeper than before, or possibilities of which DU / DI that will be the place for the PSG later.

The design of the PSG program needs to be analyzed on the suitability of Industrial Internship premises and the capabilities that must be mastered by learners based on the basic competence / competence standard stated in the syllabus. The analysis is intended to obtain information on what competencies can be learned in schools with available facilities and what competencies are learned in the workplace, a flow chart showing the design of the Industrial Internship program is presented in Fig. 3.

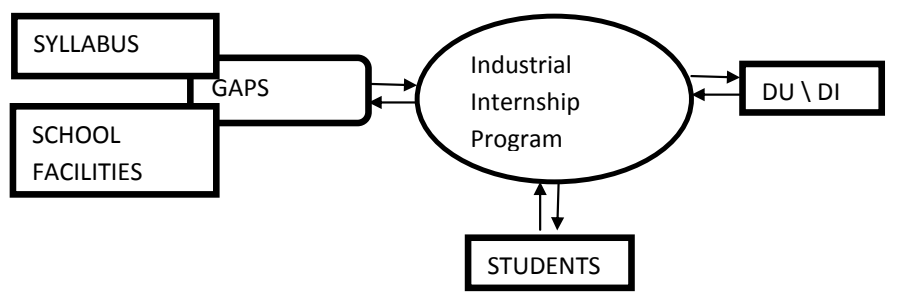

\section{B. Input}

Before conducting PSG activities, students take learning activities at school. They receive lesson materials that aren't not only related to vocational skills (vocational theory, basic professional practice and professional practice), but also general (normative) education, and supportive (adaptive) basic education. Activities at school are expected to be students' strength that could be applied in the work world.

One of the responsibilities of DU / DI is to provide PSG. Facilities here mean facilities that have a direct or indirect connection. Direct means all facilities are used for work activities. While indirect means a conducive working environment to do work activities.

As a system, if all the components involved realize their respective functions to maximize the function of the system, this program will create a permanent form of cooperation between the DU / DI and the school. Through this cooperation can be obtained output and the optimal outcome is the creation of qualified human resources in accordance with the needs of society and the labor market. To cut the gaps between school goals and the demands of the work world, the schools need to 
prepare a curriculum which content is close to what the work world expected.

\section{Process}

In implementing PSG in DU / DI expected students could be given a direct opportunity to handle work directly. Both are administrative and field work. It is hoped that this activity will provide a real working experience for the students.

Before actualizing it, it is necessary to prepare students to be mentally and physically ready. The preparation also applies in the learning process. In addition, an inventory of appropriate learning places for competency-based learning is the place where the learned competencies are implemented (the real world of work), or at least a replica of the real conditions. As directed by Ministry of Education and Culture, learners need to implement PSG in DU / DI within 2 months which is equivalent to 400 hours (Indro, 2004). However, most SMK implements PSG for 3 months.

Based on the result of Yus of, Fauzi, Abidin \& Awang (2013) research, it indicates that most industries / entrepreneurs say that 3 months for industrial training is too short and should be extended to 6 months [8]. Duration is too short because the students cannot handle the more comprehensive project. The length of the PSG is the school policy but for the minimum time still refers to the instructions of the Ministry of Education and Culture.

Schools, especially the public relations department that handles PSG need to continue to evaluate the implementation of PSG target, it means that students who perform Industrial Internship in the appropriate place and do work in accordance with the competence of expertise. Evaluation can be done based on monitoring results of supervising teacher and student on the PSG report and also input / suggestion from a supervisor. Ab Rahman et al (2009) state that the activities of planning, monitoring, and assessing the effectiveness of industrial training programs together will make the Industrial needs to be more practical and relevant [9].

\section{Product}

The products referred in this evaluation are students. So the evaluation is an evaluation of students after they do PSG. In this evaluation phase, it should be seen again that PSG is a professional skill education that systematically integrates and synchronizes educational programs in schools and skills programs gained through direct working activities in the workplace, directed to achieve a certain level of professional expertise. There are two things that need to be underlined, namely the activities of working directly in the world of work and professional skills.

In the first point, it means students can be evaluated after implementing PSG. The second point of expertise possessed should be at a certain professional level. After implementing the PSG students are expected to experience a change and possesses better skills. The ability of students in achieving the skills based the standardd can be done through the process of professional examination.

During the course of the PSG, students have mentors in the industry who will guide students during PSG and assess their technical and nontechnical performance (soft skills). After implementing the PSG, students must also write a report showing the activities carried out comprehensively. Industry parties assess the performance, quality of work, and development of student personalities during the industry and supervisor teachers will ass ess based on the results of monitoring and student reports. In addition to experience and knowledge, this value is the result of industrial implementation.

The result is something that is held (create, made, etc) by effort or effect. While Industrial Internship is an educational activity, training, and learning conducted in DU / DI that are relevant to the competence (ability) students and their field. PSG results are the results obtained by students from education, training, and learning activities conducted in the business world or industrial world. PSG results can also be interpreted as the results achieved by students during the industrial activities, assumed as a picture of the work result and ability of learners in the industry they chose.

Assessing work skills is an effective way to ensure that the skills have been developed. Assessments encourage students to identify the skills they need, the skills they need to develop, and how to develop them. Assessment can stimulate development, help students to see their skill gaps, and explain what skills are important related to the given task.

\section{CONCLUSION}

\section{A. Conclusion}

First, in the context evaluation of the evaluation objectives are: (a) the purpose of PSG in schools; (B) planning of PSG implementation; And (c) PSG needs and opportunities. Second, In the evaluation of inputs of the evaluation objectives are: (a) PSG implementation strategy, including: (1) procedures (PSG materials, implementation time, methods and implementation patterns); (2) cooperation with DU/DI (mentoring role, cooperation script, lobby). Third, In the evaluation (process) the process of evaluation objectives are: (a) the implementation of PSG i.e. time, student activity journal, implementation of guidance; (B) PSG constraints. Fourth, In the evaluation (product) product evaluation target of the students, which see the ability or competence of students in accordance with the goals proclaimed by the Ministry of Education and Culture.

\section{B. Suggestion}

Dual System Education is an education system that is expected to minimize the gap between school and work word .This concept is adopted from Germany. This country has been successfully implemented this system. The government must be 
fully engaged to all related elements / parties. To compens ate the benefits for industries that are willing to accept PSG for students, the government might provide some facilities such as tax reduction or other conveniences.

\section{REFERENCES}

[1] Anwar. 2004. Implementation of Dual System Education Program at SMK in Kendari City. Journal of Education and Cult ure, Vol. 36,13-17.

[2] Ananta, R. F. M. S. 2014. Relationship Between Value On The Job Training, Certification Training Value, Project Work Quality, and Extracurricular Value with Basic Skills (Basic Skillls) Students Mechat ronics Department SMKN 8 Malang. Thesis not published. Malang: PPs UM.

[3] Amri, S. 2013. Development \& Learning Model in Curriculum 2013. PT Pustakaraya Achievement. Jakarta.

[4] Widoyoko, Eko Putro. 2012. Evaluation of Learning Program. Yogyakarta: Pustaka Belajar.

[5] Worten, B. R. and Sanders, J. S. 1987. Educational Evaluation: Theory And Practice. London: Longman Inc.

[6] Yusof, A. N., Fauzi, S. N. F. M., Abidin, N. Z., \& Awang, H. 2013. Improving Graduates' Employability Skills through Industrial Training: Suggestions from Employers. Journal of Education and Practice, 4 (4): 23 29.

[7] Ab Rahman, M.Z., Omar, M.Z., Kofli, N.T., Mat, K., Osman, S.A., \& M Darus, Z. 2009. Assessment of Engineering Students Perception After Industrial Training Placement. European Journal of Social Sciences. 8 (3): 420-431. 